\title{
Investigation the effect of outdoor air infiltration on the heat-shielding characteristics the outer walls of high-rise buildings
}

\author{
Yu.S. Vytchikov ${ }^{1}$, A. B. Kostuganov ${ }^{1}$, M. E. Saparev ${ }^{1 *}, I$. G. Belyakov ${ }^{1}$ \\ ${ }^{1}$ Samara State Technical University, 443100, Molodogvardeyskaya St., 244, Samara, Russia
}

\begin{abstract}
The presented article considers the influence of infiltrated outdoor air on the heat-shielding characteristics of the exterior walls of modern residential and public buildings. A review of the sources devoted to this problem confirmed its relevance at the present time, especially for high-rise buildings. The authors of the article analyzed the effect of longitudinal and transverse air infiltration on the heat-shielding characteristics of the outer wall of a 25 -story building that was built in Samara. The results showed a significant reduction of the reduced resistance to the heat transfer of the outer wall when air is infiltrated through it. There are the results of full-scale examination of external walls to confirm the calculated data. Based on the results of the study carried out by the authors of the article, general recommendations on the internal finishing of the outer walls of high-rise buildings are given.
\end{abstract}

\section{Introduction}

At present, in connection with the implementation the energy saving program in the Russian Federation, significant changes have occurred in the constructive decisions of the outer walls of high-rise buildings. In the multi-storey buildings practice the most common are the exterior wall constructions shown in Figure1. The thickness of the heat- insulation material or masonry made of lightweight stones is determined based on the provision of regulatory requirements for thermal protection of buildings, guided by SP 50.13330.2012 "Thermal protection of buildings."

There are two types of air filtration in building enveloping structures - transverse and longitudinal filtration. The transverse air filtration is the movement of air in the structure, directed perpendicular to the plane of the wall surface, the longitudinal filtration -parallel to the plane of the wall. The works of Gagarin V.G., Kozlov V.G., Sadchikov A.V. [1-3, 18], Vytchikov Yu. S. [4, 6-8], Petrichenko M.R. [5] are devoted to the questions connected with research of influence of air longitudinal infiltration on heat-protective characteristics of external walls with ventilating facades [9-11, 13-17, 19-20].

Influence of longitudinal infiltration on the heat-shielding characteristics of exterior walls insulated by ventilated facades was considered in detail in work [1]. The influence of insulation density on the resistance to heat transfer of the outer wall is established on the

\footnotetext{
*Corresponding author: msx072007@yandex.ru
} 
basis of experimental and scientific studies on the example of staple glass fiber products produced by "URSA" companies. With increasing density of staple glass fiber from 15 to $50 \mathrm{~kg} / \mathrm{m}^{3}$, the coefficient of thermal effect of longitudinal filtration increases from 0.77 to 0.98 . By using mineral wool boards of increased density (more than $80 \mathrm{~kg} / \mathrm{m}^{3}$ ), the need in wind protection measures disappears. The purpose of this research is to study the effect of outdoor air infiltration on the thermal protection characteristics the exterior walls of modern high-rise buildings.

a)

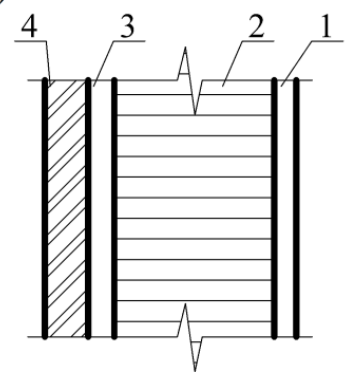

b)

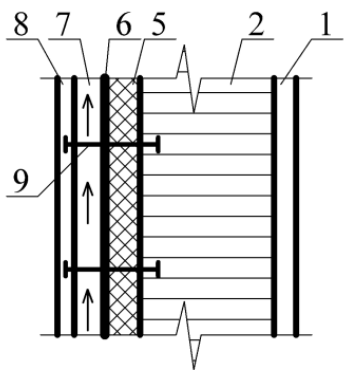

c)

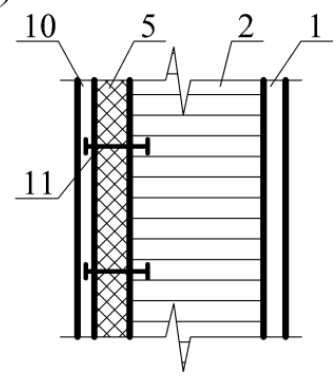

Fig.1. Constructive decisions for exterior walls of high-rise buildings: a) external wall made in the masonry's form of lightweight concrete stones; b) external wall with ventilated facade; c) external wall insulated with a facade system with thin-walled plaster: 1- internal plaster: 2- masonry from lightweight concrete stones on cement-sand or warm mortars; 3- unventilated air layer; 4- ceramic facing brick; 5- heat-insulation material; 6- windproof membrane; 7- ventilated air interlayer; 8decorative panel; 9- metal bracket; 10- texture layer of the facade system; 11- plastic dowel.

\section{Materials and Methods}

Assessment of the effect the transverse filtration of outside air on the resistance to heat transfer the outer wall of a 25 -storey building is made for the construction shown in Fig. $1 \mathrm{~b}$. The value of the heat transfer coefficient the outer wall, taking into account the infiltration of the outside air, is determined according to $[6,12]$ by the formula

$$
k=\frac{c_{p} \cdot G \cdot e^{c_{p} \cdot G \cdot R_{0}^{\text {usl. }}}}{e^{c_{p} \cdot G \cdot R_{0}^{u s s .}}-1}, \mathrm{~W} /\left(\mathrm{m}^{2} \cdot{ }^{0} \mathrm{C}\right)
$$

Where $c_{p}$ is the specific isobaric heat capacity of the air, $\mathrm{J} /\left(\mathrm{kg} \cdot{ }^{0} \mathrm{C}\right) ; \mathrm{G}$ - air permeability of the outer wall, $\mathrm{kg} /\left(\mathrm{m}^{2} \cdot \mathrm{h}\right) ; R_{0}^{u s l}$ - resistance to heat transfer from smooth surface the outer wall, $\left(\mathrm{m}^{2} \cdot{ }^{0} \mathrm{C}\right) / \mathrm{W}$.

According to SP 50.13330.2012 the air permeability of the outer wall is determined by the formula

$$
G=\frac{\Delta P}{R u}, \mathrm{~kg} /\left(\mathrm{m}^{2} \cdot \mathrm{h}\right)
$$

Where $R u=\sum_{i=1}^{n} R_{u i}$ - resistance to air permeability of the outer wall, $\left(\mathrm{m}^{2} \cdot \mathrm{h} \cdot \mathrm{Pa}\right) / \mathrm{kg}, R_{u i-}$ resistance to air permeability of the i-th layer of the outer wall, $\left(\mathrm{m}^{2} \cdot \mathrm{h} \cdot \mathrm{Pa}\right) / \mathrm{kg}$.

To determine the air permeability of the outer wall, it is necessary to have information on the coefficients of air permeability of the used materials, which are determined reference from the normative literature. 
At present, there is no information on the air permeability of facade systems using thinwalled plasters, in the accredited Laboratory of Thermal Engineering Testing ACI SamSTU the air permeability of the most common heat insulation materials was tested on an aerodynamic stand, which was developed by the laboratory staff. The results of the investigations are presented in works [6-11].

The carried out tests of texture layers of facade systems on acrylic and silicate bases did not reveal their air permeability because of the presence of glue compositions in them, that's why the external walls, insulated with facade systems with thin-walled plaster, are practically impenetrable.

In addition to tests to determine the air permeability of building materials, the ACI SamSTU staff carried out a thermal imaging survey of the heat-shielding characteristics of external walls with ventilated facades of a 25 -story building built in Samara.

Determination of heat engineering indicators of building enclosing structures was made in accordance with the requirements of Russian Standard GOST 31937-2011 «Buildings and structures. Rules for inspection and monitoring of technical condition».

The composition of works for determination of the thermal protection properties of building enclosing structures includes thermal imaging of building enveloping structures to identify places with low thermal protection indicators, performed in accordance with the requirements of Russian Standard GOST of Russia 54852-2011 "Buildings and structures. Method of thermal imaging control of insulation quality of enclosing structures".

Thermal imaging control is carried out under the close to the stationary heat transfer regime through the enclosing construction. To be surveyed surfaces should not be in the direct and reflected solar irradiation zone for 12 hours before the measurements are taken. Surfaces of enclosing structures should not be subjected to additional thermal effects from biological objects and lighting sources in the period of thermal imaging.

On the results of the thermal imaging survey, nodes of junction of enclosing structures with low heat-shielding characteristics are determined.

Thermal imager under certain temperature-humidity conditions makes it possible to determine: defects of structures connected with high humidity and leaks; presence of infiltration air flows passing through the fence due to cracks in it, poor sealing of joints, poor quality of construction and installation works, insufficient compaction of window and door structures; sections on enclosing structures, having a lower thermal resistance.

The advantages of using an infrared camera include: the speed of the survey, the contactless method of obtaining data, the absence of evacuation of people during the survey, a visual representation of the data and the presence of a sufficiently high memory (up to 200 images).

Thermal imaging is performed in infrared light. The thermal imager provides a color image of the observed object, due to this fact, it is possible to analyze in detail the state of the enclosing structures. With its help, it is possible to detect both defects in construction and installation works and design solutions of enclosing structures.

Based on the results of the thermal imaging survey of the facades of the surveyed building, the specific heat flux through the outer enclosing structures is determined by formulas

$$
\begin{aligned}
& \mathrm{q}=\alpha_{\mathrm{N}}\left(\overline{\tau_{\mathrm{N}}}-\mathrm{t}_{\mathrm{N}}\right), \mathrm{W} / \mathrm{m}^{2} \\
& \mathrm{q}=\alpha_{\mathrm{B}}\left(\mathrm{t}_{\mathrm{B}}-\overline{\tau_{\mathrm{B}}}\right), \mathrm{W} / \mathrm{m}^{2}
\end{aligned}
$$

Where $\alpha_{N}, \alpha_{B}-$ heat transfer coefficients on the side of the outer and inner surfaces,

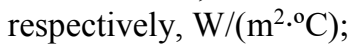


The formula (3) is used in the case when using a thermal imager a temperature field on the outer surface of the enclosing structure is determined, formula (4) - on the inner surface.

Heat transfer coefficients $\alpha_{\mathrm{H}}$ and $\alpha_{\mathrm{B}}$ are determined by the results of measurements in accordance with the methodology set forth in GOST of Russia 54852-2011.

By working with a thermal imager, follow the recommendations given in GOST of Russia 54852-2011.

Resistance to heat transfer of building enclosing structures is determined in accordance with GOST of Russia 54852-2011 by formula

$$
R_{0}=\frac{t \text { int } t_{n}}{\mathrm{q}},\left(\mathrm{m}^{2} \bullet{ }^{\circ} \mathrm{C}\right) / \mathrm{W},
$$

where $\mathrm{t}_{\text {int }}$ - internal air temperature, ${ }^{\circ} \mathrm{C} ; \mathrm{t}_{\mathrm{n}}$, - outdoor temperature, ${ }^{\circ} \mathrm{C} ; \mathrm{q}$ is the specific heat flux, $\mathrm{W} / \mathrm{m}^{2}$.

\section{Results}

We estimate the influence of plaster layers on the resistance of air permeability to external walls with ventilated facades and protected with facing brick. As an example, consider a 25 -storey building with a warm attic built in Samara. The external walls are made in the form of a brick ceramic masonry on a cement-sand mortar with a thickness of $380 \mathrm{~mm}$. On the outside, they are insulated with basalt slabs VENTI-BATTS $150 \mathrm{~mm}$ thick, protected by a windproof membrane such as Isospan $A$ and a ventilated facade made of porcelain stoneware.

As possible plasters, we will consider cement-sand and lime-sand mortars, as well as dry plaster in the form of gypsum board sheets. According to SP 50.13330.2012, the plasters mentioned above have the air permeability resistance values shown in Table 1.

Table 1. Thermal protective characteristics of finishing materials.

\begin{tabular}{|c|c|c|c|}
\hline $\begin{array}{c}\text { Denomination of the } \\
\text { finishing material }\end{array}$ & $\begin{array}{c}\text { Density in dry } \\
\text { condition, } \rho_{0} \mathrm{~kg} / \\
\mathrm{m}^{3}\end{array}$ & $\begin{array}{c}\text { Layer thickness, } \\
\mathrm{m}\end{array}$ & $\begin{array}{c}\text { Resistance to air } \\
\text { permeability, } R_{u}, \\
(\mathrm{M} 2 \cdot \mathrm{h} \cdot \mathrm{Pa}) / \mathrm{kg}\end{array}$ \\
\hline Cement-sand mortar & 1800 & 0,02 & 497 \\
\hline Lime-sand mortar & 1600 & 0,02 & 189 \\
\hline $\begin{array}{c}\text { Gypsum sheets (dry } \\
\text { plaster) }\end{array}$ & 800 & 0,0125 & 25 \\
\hline
\end{tabular}

The location of the above materials in the outer wall is shown in Fig. 1b. Resistance of heat transfer of homogeneous construction, calculated according to the procedure set out in SP 50.13330.2012, was $R_{0}^{u s l}=4,34\left(\mathrm{~m}^{2.0} \mathrm{C}\right) / \mathrm{W}$, the reduced total thermal resistance $R_{0}^{p r}=3,47\left(\mathrm{~m}^{2.0} \mathrm{C}\right) / \mathrm{W}$, which fits the regulatory requirements for residential buildings in the Samara region $\left(R_{0}^{t r}=3,47\left(\mathrm{~m}^{2.0} \mathrm{C}\right) / \mathrm{W}\right)$.

Evaluation of the transverse infiltration of air to the resistance to heat transfer of the unplastered outer wall is performed using formulas (1) and (2). The results of the calculation are presented in Table 2 . 
Table 2. Results of calculating the resistance to air permeability of a high-rise building with a ventilated facade.

\begin{tabular}{|c|c|c|c|c|c|c|c|c|}
\hline \multirow[t]{2}{*}{$\begin{array}{c}\text { Floor } \\
\text { Num } \\
\text { ber }\end{array}$} & \multirow[t]{2}{*}{$\begin{array}{l}\mathbf{H}, \\
\mathbf{m}\end{array}$} & \multirow[t]{2}{*}{$\Delta \mathbf{P}, \mathbf{P a}$} & \multirow[t]{2}{*}{$\underset{\mathrm{kg} / \mathrm{m}^{2} \cdot \mathrm{h}}{\mathrm{G},}$} & \multirow[t]{2}{*}{$\begin{array}{c}\mathbf{k}, \\
W / \mathbf{m}^{2} \cdot{ }^{0} \mathrm{C}\end{array}$} & \multirow{2}{*}{$\begin{array}{l}\text { Resistance to } \\
\text { heat transfer } \\
\text { under } \\
\text { the influence of } \\
\text { infiltration } \\
\left(R_{0}^{u s l}\right)_{u t} \text {, } \\
\left(\mathbf{m}^{2 \cdot 0} \mathrm{C}\right) / \mathbf{W}\end{array}$} & \multicolumn{2}{|c|}{$\begin{array}{c}\text { Resistance to air } \\
\text { permeability, } \\
\left(\mathbf{m}^{2} \cdot \mathbf{h} \cdot \mathrm{Pa}\right) / \mathrm{kg}\end{array}$} & \multirow{2}{*}{$\begin{array}{l}\text { Difference } \\
R_{u}^{t r}-R_{u}, \\
\left(\mathbf{m}^{2} \cdot \mathbf{h} \cdot \mathbf{P a}\right) / \mathbf{k g}\end{array}$} \\
\hline & & & & & & $\begin{array}{c}\text { The } \\
\text { required } \\
R_{u}^{t r}\end{array}$ & $R_{u}$ & \\
\hline 1 & 79 & 119 & 4,96 & 1,380 & 0,720 & 238,0 & 24 & 214,0 \\
\hline 3 & 73 & 110,9 & 4,62 & 1,290 & 0,780 & 221,8 & 24 & 198,0 \\
\hline 5 & 67 & 102,8 & 4,28 & 1,197 & 0,835 & 205,6 & 24 & 181,6 \\
\hline 7 & 61 & 94,7 & 3,95 & 1,107 & 0,903 & 189,4 & 24 & 165,0 \\
\hline 9 & 55 & 86,6 & 3,81 & 1,020 & 0,980 & 173,2 & 24 & 149,0 \\
\hline 12 & 46 & 74,5 & 3,10 & 0,880 & 1,140 & 149,0 & 24 & 125,0 \\
\hline 15 & 37 & 62,3 & 2,60 & 0,760 & 1,320 & 124,6 & 24 & 101,0 \\
\hline 20 & 22 & 42,1 & 1,75 & 0,553 & 1,810 & 84,2 & 24 & 60,0 \\
\hline 25 & 7 & 21,9 & 0,91 & 0,378 & 2,650 & 43,8 & 24 & 19,8 \\
\hline
\end{tabular}

The Analyze of the influence of longitudinal infiltration on the value of the reduced total thermal resistance of the considering external wall, carried out according to the procedure described in the work [1], showed that for plates of basalt fiber with a density of 80 to $90 \mathrm{~kg} / \mathrm{m}^{3}$, the coefficient of thermal effect of longitudinal filtration is close to 1 because of a sufficiently high density.

\section{Discussion}

From the results of calculations presented in Table 2 it follows that when the external walls are passed without internal finishing, which is done quite often, the heat-shielding characteristics $\left(R_{0}^{u s l}\right)_{u t}$ and $R_{u}$ significantly do not meet the regulatory requirements. Herewith the greatest discrepancy is observed on the lower floors.

Along with the calculated data, the negative influence of infiltration on the heatshielding characteristics of the enclosing structures is confirmed by the results of field surveys the outer walls of high-rise buildings. Fig. 2 shows a thermogram of the inner surface of the outer wall, obtained from the thermal imaging survey of the enclosing structures of a residential apartment located on the fifth floor of a 25-storey residential building. The interior decoration of the outer walls was made with a Gypsum mortar, which does not have the necessary resistance to air permeability.



Arl Average Temperature

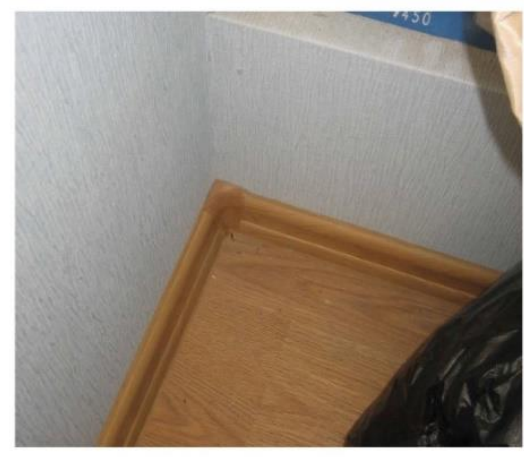

$4.0^{\circ} \mathrm{C}$

Fig. 2. Thermogram of the inner surface of the outer wall 
Thermal imaging of internal surfaces enclosing structures revealed areas of low temperatures in the lower part of the outer wall. At the same time, lower internal air temperatures, which do not meet regulatory requirements, were also recorded. In order to the exterior wall of the residential building to fit with regulatory requirements, it is necessary to plaster its inner surface.

\section{Conclusions}

Analyzing the calculated data, we can conclude that the use of cement-sand mortar as a finishing layer allows achieving the standard values of resistance to heat transfer on all floors. Lime-sand mortar can be recommended for use on the upper floors, starting with the fifth. Drywall sheets should not be used in buildings with a ventilated facade in view of the low resistance value of air permeability.

\section{References}

1. V. G. Gagarin, V. V. Kozlov, A. V. Sadchikov, Accounting of longitudinal infiltration of air at assessing the thermal wall protection of with a ventilated facade, Industrial and civil construction, 6, 42-45 (2005)

2. V. G. Gagarin, V. V. Kozlov, A. V. Sadchikov, I. A. Mehnetsov, Longitudinal air filtration in modern enclosing structures, $A B O K, \mathbf{8}, 66-70$ (2005)

3. V. G. Gagarin, V. V. Kozlov, A. V. Sadchikov, About the effect of longitudinal air filtration on the heat protection of walls with a ventilated facade, Stroyprofile, 6, 34-35 (2005)

4. Yu. S. Vychtikov, A. Yu.Vychtikov, Investigation of the effect of longitudinal and transverse air infiltration on the heat-shielding characteristics the external walls of a production building insulated with a ventilated facade, Improving the energy efficiency of buildings and structures, 3, 20-26 (2008)

5. M. R. Petrichenko, M. V. Petrochenko, Hydraulics of free convection currents in enclosing structures with an air gap, Engineering and Construction Journal, 8, 51-56 (2011)

6. Yu. S. Vytchikov, A. V. Chereneva, An experimental study of air permeability of sandless claydite-concrete, Building Materials, 7, 10-11 (2011)

7. Yu. S. Vytchikov, A. V. Sidorova, The organization of air exchange in modern energyefficient buildings, Bulletin of SGASU

8. Yu. S. Vytchikov, A. V. Sidorova, Experimental study of enclosing structures in fullscale conditions, Traditions and innovations in construction and architecture: materials of the 71st All-Russian Scientific and Technical Conference on the results of research work of 2013, 284-286 (2014)

9. S. F. Korenkova, Yu. V. Sidorenko, Unfilled foam concrete, Scientific Review, 4, 106107 (2014)

10. A. S. Pershina, S. F. Korenkova, The most important components of facade compositions, Traditions and innovations in construction and architecture: materials of the 69th All-Russian Scientific and Technical Conference on the results of research work in 2011, 166-167 (2012)

11. A. S. Pershina, S. F. Korenkova, Decorative nano-filled cement-polymer compositions for finishing facades, Nanotechnology in construction: a scientific online journal, $\mathbf{4}$, 36-46 (2011) 
12. N. N. Razumov, F. V. Ushkov, I. S. Shapovalov, Resistance to heat transfer and winter design temperatures for heating engineering, $A B O K, \mathbf{5}, 78-81$ (2011)

13. N. P. Umnyakova, A. A. Verkhovsky, Estimation of air permeability of the building's enclosing structures, $A B O K$, 5, 48-53 (2013)

14. N. P. Umnyakova, Thermal protection properties of exploited hinged ventilated facade structures, Housing construction, 2, 2-6 (2011)

15. P. N. Umnyakov, Infiltration and exfiltration influence on the thermal protection of enclosing structures with considering the porosity of materials, Housing construction, 10, 46-50 (2014)

16. A. V. Maltsev, D. S. Sorokin, Energy saving in multi-storey residential buildings with air infiltration through the outer wall, New University, 3-4, 87-90 (2015)

17. V. M. Valov, Breathable enclosing structures in a building system, Bulletin of the Siberian State Automobile and Highway Academy, 19, 33-37 (2011)

18. V. G. Gagarin, S. V. Gouvernyuk, A. S. Kubenin, P. P. Pastushkov, V. V. Kozlov, To the methodology for calculating the influence of wind impact on the air conditions of buildings, News of Higher Educational Institutions, The textile industry technology, 4, 234-240 (2016)

19. I. L. Shubin, A. I. Ananiev, Thermal protection properties and air permeability of ceramic Isoterex blocks in wall masonry, Industrial and civil construction, 3, 57-59 (2013)

20. A. D. Zhukov, T. V. Smirnova, A. V. Chugunkov, Heat transfer in high-porous materials, Internet-Vestnik VolgGASU, 3, 8 (2012) 